\title{
TECNOLOGIAS DIGITAIS E TRABALHOS EM GRUPO: relações produzidas por estudantes de licenciaturas
}

\author{
Mariana Aparecida Toledo de LIMA ${ }^{1}$ \\ Silvana Claudia dos SANTOS ${ }^{2}$
}

\begin{abstract}
Resumo
Este artigo apresenta as perspectivas de estudantes de licenciaturas sobre a utilização de tecnologias digitais associadas à metodologia de trabalhos em grupo. Com base em uma abordagem qualitativa de pesquisa, utilizaram-se questionários fechados e entrevistas semiestruturadas para a produção dos dados. Partindo de uma visão teórica que compreende qualquer tecnologia como um produto humano capaz de condicionar a cultura e a sociedade, abordaram-se, especificamente, os usos das tecnologias digitais quando associadas à metodologia de ensino que inclui a mobilização de trabalhos em grupo. Os resultados apontaram que o cenário contemporâneo encontra-se delineado pela coexistência de diferentes tipos de tecnologias. Particularmente, emergem, neste cenário, formas variadas de interação e comunicação provenientes do uso de tecnologias digitais. Os dados indicam, ainda, que a realização de trabalhos em grupo como metodologia de ensino vem sendo permeada por tecnologias digitais, evidenciando limites e possibilidades para o campo educacional.
\end{abstract}

Palavras-chave: Tecnologias na Educação. Interação. Comunicação. Cooperação. Colaboração.

\footnotetext{
${ }^{1}$ Professora de História na rede pública estadual de Minas Gerais. Mestre em Educação pela Universidade Federal de Viçosa - UFV. Membro do Grupo de Atenção às Tecnologias na Educação - GATE.

E-mail: marianatlima@outlook.com

2 Doutora em Educação Matemática pela Universidade Estadual Paulista “Júlio de Mesquita Filho” UNESP. Docente do Departamento de Educação e do Programa de Pós-graduação em Educação da Universidade Federal de Viçosa - UFV. Coordenadora do Grupo de Atenção às Tecnologias na Educação - GATE e membro associada do Grupo de Pesquisa em Informática, outras Mídias e Educação Matemática - GPIMEM.

E-mail: silvana.santos@ufv.br
} 


\title{
DIGITAL TECHNOLOGIES AND GROUP WORK: relationships produced by teaching degree students
}

\author{
Mariana Aparecida Toledo de LIMA \\ Silvana Claudia dos SANTOS
}

\begin{abstract}
This article presents the perceptions of teaching degree students on the use of digital technologies associated with the methodology of group work. Based on qualitative research, closed questionnaires and semi-structured interviews were applied to produce data. Starting from a theoretical view that comprehends any technology as a human product capable of conditioning culture and society, the uses of digital technologies were specifically addressed when associated with the teaching methodology that involves group work. The results showed that the contemporary scenario is outlined by the coexistence of different types of technologies. In particular, different forms of interaction and communication arising from the use of digital technologies emerge in this scenario. The data also indicate that group work as a teaching methodology has been permeated by digital technologies, showing limits and possibilities for the educational field.
\end{abstract}

Keywords: Technologies in Education. Interaction. Communication. Cooperation. Collaboration. 


\section{Introdução}

Como uma instituição que oportuniza relações não apenas com o saber, Outeiral (1997, p. 361) aponta que a escola, “como uma atividade eminentemente grupal, também tem funções de sociabilização”. Numa simulação da vida, a escola atua como uma microssociedade em que, na busca por sua identidade, o estudante "compete, divide, rivaliza, oprime e é oprimido, ou seja, reproduz o sistema social.” (OUTEIRAL, 1997, p. 361) Quanto à sociedade, o que ela requer da escola é que seja "uma instituição normativa que trate de transmitir a cultura, incluindo aí, é certo, não apenas conteúdos acadêmicos, mas, e principalmente, seus elementos éticos e estruturais.” (OUTEIRAL, 1997, p. 363) Seu currículo precisa ser construído em torno desses princípios, de modo que, na ausência de consonância, a sociedade "trata de submetê-la a seus objetivos" (OUTEIRAL, 1997, p. 363).

Quando falamos em escola, a intenção é a de nos referirmos, de modo geral, à educação. Sendo assim, no ensino superior não é diferente. Ao adentrarmos no âmbito educacional, a sua relação com a sociedade é imanente, de modo que as demandas sociais permeiam esse campo. Desse modo, questões relacionadas à utilização das tecnologias digitais $^{3}$ e ao mercado de trabalho, bem como suas exigências passam também a incorporar as demandas estudantis, de forma que os alunos visam, em seu período de formação, um momento de preparação para a sua área de atuação profissional.

No contexto das exigências contemporâneas, a metodologia de trabalho em grupo encontra-se, por vezes, vinculada às necessidades do mercado de trabalho. Assim, tanto no âmbito das discussões em torno da aprendizagem como no das exigências para esse mercado, encontramos a marca do processo de desenvolvimento das relações interpessoais, capaz de possibilitar aos indivíduos "gerir os vários conflitos (identitários)” configurados pelas constantes mudanças por que passa a sociedade ocidental (MACHADO; CÉSAR, 2012, p. 100).

Em relação às tecnologias digitais, também no âmbito laboral, elas configuram "uma forma de trabalho antes considerada improdutiva em muitas modalidades: o trabalho imaterial” (HYPOLITO; GRISHCKE, 2013, p. 509), emergindo, nesse novo contexto, a informação como produtora dos "fluxos dos novos espaços de produção e reprodução social” (Ibidem).

Relacionado a esses aspectos, este artigo é fruto de uma pesquisa com a finalidade investigar o papel das tecnologias digitais quando associadas aos trabalhos em grupo desenvolvidos por licenciandos (LIMA, 2019). De maneira mais específica, buscou-se identificar: quais são essas tecnologias e como elas vêm sendo utilizadas; que

3 Optamos por utilizar o termo "tecnologias digitais" ao nos referirmos à informatização cuja principal tendência é, conforme Lévy (2010), a digitalização, abrangendo todas as técnicas referentes à informação e à comunicação. Embora reconheçamos que as tecnologias são tão antigas quanto a espécie humana e que envolvem muito mais que artefatos, neste artigo, toda vez que utilizamos a palavra “tecnologia ou tecnologias” estamos nos referindo às “tecnologias digitais”, com o intuito de evitar repetições e garantir maior fluência ao texto. 
possibilidades e desafios os estudantes consideram ter que enfrentar na realização dos trabalhos em grupo; bem como de que modo as tecnologias digitais vêm interferindo na produção coletiva de conhecimento. Para tal, o estudo baseou-se numa abordagem qualitativa, cujos participantes eram licenciandos provenientes de duas turmas, em disciplinas distintas, de uma Universidade Federal mineira. Para a produção dos dados, nas disciplinas, foram aplicados questionários fechados e realizadas entrevistas semiestruturadas com alguns licenciandos.

Durante a produção de dados, foi possível: identificar as tecnologias digitais utilizadas pelos estudantes, quando trabalham em grupo, e de que maneira eles a utilizam; compreender o modo como as tecnologias vêm interferindo na produção coletiva de conhecimento; além de inferir como esses futuros professores compreendem os trabalhos em grupo enquanto uma metodologia com foco na aprendizagem. Para este artigo, trouxemos reflexões e problematizações em torno das conceituações sobre grupo, das suas caracterizações, de suas possibilidades referentes à potencialização do processo de aprendizagem a partir dessa forma de trabalho, bem como em torno dos desafios que podem emergir dessa metodologia. Quanto à utilização das tecnologias digitais associadas aos trabalhos em grupo, destacaremos o modo como ocorre a comunicação entre os estudantes, assim como os limites e as possibilidades relativos ao uso dessas tecnologias, tanto no que concerne à questão comunicacional, como no que se refere à produção de conhecimentos.

\section{Trabalhos em grupo na educação}

A proposta de realização de trabalhos em grupo é apontada, por alguns autores, como "uma importante estratégia de trabalho no mundo da educação - tal como antes já tinha acontecido no mundo da ciência e no mundo empresarial” (BOAVIDA; PONTE, 2002, p. 2). Há alguns séculos, educadores utilizam-se dessa prática de trabalho por acreditar "em seu potencial de preparar alunos para enfrentar a realidade profissional" (TORRES; IRALA, 2014, p. 62). Segundo Cohen e Lotan (2017), essa forma de trabalho pode ser utilizada pelo professor, caso ele tenha como finalidade a construção de uma aprendizagem ativa. Desse modo, "o trabalho em grupo, planejado intencionalmente, é uma ferramenta poderosa, que oferece oportunidades simultâneas para todos.” (COHEN; LOTAN, 2017, p. 1)

A estruturação dessa atividade, nesse caso, é essencial, pois "se feito de maneira não estruturada, pode acarretar uma série de problemas. Não necessariamente os estudantes e os próprios adultos sabem como trabalhar em conjunto de forma exitosa, por isso, é necessário aprender como se trabalhar assim.” (COHEN; LOTAN, 2017, p. 3) Esta é uma metodologia que pode favorecer os estudantes frente à aprendizagem conceitual e, por ser relativa a processos sociais, pode também potencializar "as relações intergrupais, aumentando a confiança e a cordialidade. Ensina habilidades para atuar em equipe que 
podem ser transferidas para muitas situações, que sejam escolares ou da vida adulta" (COHEN; LOTAN, 2017, p. 7). Conforme Damiani (2008, p. 224-225), essa metodologia possibilita que se resgate "valores como o compartilhamento e a solidariedade - que se foram perdendo ao longo do caminho trilhado por nossa sociedade, extremamente competitiva e individualista."

No campo educacional, por sua vez, essa metodologia representa uma "rejeição ao autoritarismo, à condução pedagógica com motivação hierárquica, unilateral”, além de ser, também, um modo de "concretizar uma socialização não só pela aprendizagem, mas principalmente na aprendizagem.” (TORRES; ALCÂNTARA; IRALA, 2004, p. 6) Seria ela, conforme Torres e Irala (2014, p. 69), um método de "oposição ao sistema de ensino dominante, baseado numa pedagogia autoritária, hierárquica e unilateral”.

Ademais, a metodologia de trabalhos em grupo, segundo Torres e Irala, é reconhecida no campo educacional como uma prática que pode potencializar os processos de ensino e aprendizagem, promovendo

[...] uma aprendizagem mais ativa por meio do estímulo: ao pensamento crítico; ao desenvolvimento de capacidades de interação, negociação de informações e resolução de problemas; ao desenvolvimento da capacidade de autorregulação do processo de ensino-aprendizagem. (TORRE; IRALA, 2014, p. 61)

Torres e Irala (2014) afirmam, ainda, ser a construção do conhecimento algo social, produto das interações interpessoais, e não algo meramente transmissível pelo professor (TORRES; IRALA, 2014). Assim, o professor deixa de ser o centro dos processos de ensino e aprendizagem e o aluno pode ocupar uma posição de sujeito ativo, neles exercendo um papel fundamental.

O modo como essa atividade é estruturada, por sua vez, confere o sucesso do trabalho nos processos de ensino e aprendizagem (COHEN; LOTAN, 2017). As possibilidades de ensinar e de aprender, provenientes das relações interpessoais, enriquecem o raciocínio, na medida em que a diversidade, de perspectivas e de experiências, proveniente de cada integrante do grupo compõe o trabalho. Nesse sentido, como apontam Torres e Irala (2014, p. 89), "essa é a principal contribuição da Aprendizagem Colaborativa: a interação sinérgica entre indivíduos que pensam diferente, a vivência desse processo e a construção de um produto que somente pode ser alcançado com a contribuição de todos os envolvidos.”

\section{Trabalho colaborativo e trabalho cooperativo}

É comum encontrarmos, na literatura relativa à metodologia de trabalhos em grupo, uma divisão ou alternância de termos entre: trabalho colaborativo e trabalho cooperativo. Há estudos que consideram essas duas expressões como alusivas a formas distintas de atividade, atribuindo características próprias a cada um desses trabalhos. 
Isso se justifica, segundo Torres, Alcântara e Irala (2004, p. 3), pelo fato de que "cada um deles, ao longo dos anos, desenvolveu distinções próprias e diferentes práticas em sala de aula."

O trabalho colaborativo é caracterizado por uma relação de reciprocidade entre os membros do grupo, além de haver nele uma interação maior entre os integrantes para que haja colaboração. Esse tipo de trabalho deve ser espontâneo e isento de hierarquia, de modo que sua base de igualdade esteja na ajuda mútua entre seus membros, a fim de alcançar um objetivo comum que beneficie a todos (BOAVIDA; PONTE, 2002). É, considerado, portanto, "mais profundo e complexo que o cooperativo" (TORRES; IRALA, 2014, p. 69), que se caracterizaria por ser, de certo modo, mais simples e bem definido, sem possibilidade de alterações no seu decurso. Desse modo, teria como propósito "produzir determinado efeito; funcionar ou fazer funcionar de acordo com um plano ou sistema." (BOAVIDA; PONTE, 2002, p. 4)

Além dessas distinções, autores como Fiorentini (2006), Boavida e Ponte (2002) apontam, também, algumas diferenciações dentro do próprio trabalho caracterizado como colaborativo. Ao embasar-se em Hargreaves (1998), Fiorentini (2006 ) afirma que um grupo autenticamente colaborativo caracterizar-se-ia por ser constituído voluntariamente, ou seja, composto por vontade espontânea das pessoas que o integram, "sem serem coagidas ou cooptadas por alguém a participar” (FIORENTINI, 2006, p. 54-55). Além disso, o entendimento mútuo entre os membros do grupo - trabalhando em prol de um fim comum - e a negociação entre eles são características fundamentais desse trabalho do tipo colaborativo. Divergente dessa colaboração espontânea, conforme Boavida e Ponte (2002, p. 5), a colaboração proposta seria "determinada por instâncias superiores com autoridade para o fazer”, o que poderia levá-la ao insucesso quando não bem aceita pelos integrantes. Logo, estar trabalhando em grupo não significaria, necessariamente, estar trabalhando de forma colaborativa.

O despontar da ideia de um fim comum dentro do grupo demanda tempo (FIORENTINI, 2006). Em um grupo autenticamente colaborativo, como coloca Fiorentini (2006, p. 58), "a busca de um entendimento comum tem relação com a construção de um sentimento de pertencimento e de compromisso compartilhado com o projeto e trabalho do grupo" e independe, por exemplo, da presença de um líder ou de uma liderança compartilhada. Se um grupo é de fato colaborativo, todos os seus membros assumem responsabilidades, sendo todos protagonistas, indivíduos que aprendem, ensinam e produzem conhecimentos (FIORENTINI, 2006).

Ademais, o êxito desse grupo baseia-se no diálogo e na confiança necessários entre os seus integrantes. Uma vez que nenhum grupo está isento de desentendimentos, Boavida e Ponte (2002, p. 7) apontam a relação dialógica como essencial, pois "é fundamental que seja aceite a voz pessoal, decorrente da experiência, e, por outro lado, é necessário ter sempre presente que nenhuma ideia é definitiva.” A confiança, por sua vez, 
é também apontada como "fundamental para que os participantes se sintam à vontade em questionar abertamente as ideias, valores e aç̧ões uns dos outros, respeitando-os e sabendo, igualmente, que o seu trabalho e os seus valores são respeitados.” (BOAVIDA; PONTE, 2002, p. 7)

\section{Tecnologias digitais na educação}

Um contexto muito específico é caracterizado pelo avanço das tecnologias digitais. Nele, a atenuação das fronteiras e das distâncias e a velocidade das informações assinalam uma sociedade globalizada marcada pela "troca e/ou comunicação de informações à medida que elas são produzidas; ação à distância; aceleração das interdependências (econômicas, sociais, culturais, financeiras, energéticas, climáticas etc.); mundo virtual (on-line, redes)” etc. (AKKARI, 2011, p. 22).

Nessa conjuntura, "a cibercultura acaba propiciando o surgimento de novas práticas e atitudes que passam a ser valorizadas dentro dos mercados econômicos dos países e acarreta consequências para a educação.” (FARIAS; DIAS, 2013, p. 90) Os recursos antes disponíveis para ministrar uma aula "limitavam-se basicamente aos livros e quadro de giz, mas, contemporaneamente os recursos com computadores, com acesso à internet têm contribuído para ampliar o ambiente educacional.” (SANTOS; ALVES; PORTO, 2018, p. 45) Ademais, com a internacionalização das políticas públicas educacionais, as tecnologias digitais emergem dentro dos novos conceitos e paradigmas como uma possibilidade para a educação (AKKARI, 2011).

O problema da internacionalização dessas políticas está, entretanto, na homogeneização dos modelos educacionais, o que torna o sistema educacional monolítico. Ainda que cada país possua sua singularidade, esses modelos tendem à universalização. Dessa forma, a distribuição desigual da internet pelo planeta, por exemplo, é desprezada. No ano de 2016, a Organização das Nações Unidas (ONU) divulgou fatos que apontam para essa desigualdade, a partir dos seguintes dados apresentados pela ICT Facts \& Figures 2016, referentes à penetração da internet no mundo: 81\% nos países desenvolvidos; $40 \%$ nos emergentes; e 15\% nos países mais pobres.

Além disso, para que as tecnologias digitais sejam utilizadas no campo educacional, é necessário aprendizado e empenho de todos os que vão mobilizá-las, além de serem essenciais, também, as estruturas físicas adequadas. De acordo com Bernstein (2001), analisado por Santos, Alves e Porto (2018, p. 45), "compreender a tecnologia é assumi-la como fonte de um novo potencial intelectual." Como corroboram Soares e Vasconcelos (2018, p. 2), no caso dos docentes, é necessário que lhes sejam propiciados elementos pedagógicos para a sua familiarização "com as tecnologias, [pois] somente assim, se concretizará a sua alfabetização tecnológica.”

Quando bem utilizadas, as tecnologias digitais podem contribuir com os processos de ensino e de aprendizagem no sentido de provocar "a alteração dos 
comportamentos de professores e alunos, levando-os ao [...] maior aprofundamento do conteúdo estudado.” (KENSKI, 2007, p. 45) Santos, Alves e Porto (2014, p. 46) afirmam ainda que "a inserção das tecnologias em sala de aula torna-se uma estratégia que aproxima o discente da realidade, uma vez que elas fazem parte do contexto social, cumprindo um movimento de socialização e compartilhamento da produção de conhecimentos.”

Para que se consiga alterar o processo educativo por meio delas, entretanto, é necessário que sejam compreendidas e incorporadas pedagogicamente, de modo que deixem de ser apenas mais um recurso didático (KENSKI, 2007).

\section{O percurso metodológico}

A pesquisa teve como lócus de estudo a Universidade Federal de Viçosa, localizada na Zona da Mata de Minas Gerais. Nela, duas disciplinas relacionadas ao campo da Educação foram selecionadas: uma obrigatória para todas as licenciaturas, abrangendo estudantes de variados cursos e períodos; e outra obrigatória para o curso de Pedagogia, pois, levamos em consideração a especificidade curricular deste curso, cujos alunos não realizam as disciplinas obrigatórias com as outras licenciaturas. A justificativa para essa seleção baseia-se na premissa de que uma maior variedade de estudantes nos proporcionaria, consequentemente, perspectivas diversas acerca da proposta de estudo.

Dessa maneira, utilizando uma abordagem qualitativa de pesquisa, os instrumentos de produção de dados foram: o questionário fechado, aplicado aos estudantes das duas disciplinas selecionadas; e a entrevista semiestruturada, realizada apenas com alguns discentes, selecionados a partir do questionário. Realizadas na própria Universidade, todas as entrevistas foram registradas em áudio e, posteriormente, transcritas na íntegra.

No momento da aplicação dos questionários, tanto na disciplina EDU 144 Estrutura e Funcionamento do Ensino Fundamental e Médio -, obrigatória para todas as licenciaturas, como na EDU 461 - Ensino de Matemática I -, obtivemos a participação de 50 licenciandos, totalizando 100 alunos de 10 cursos distintos, conforme demonstrado, a seguir, no Gráfico 1: 
Gráfico 1 - Cursos dos participantes da pesquisa

Curso

100 respostas

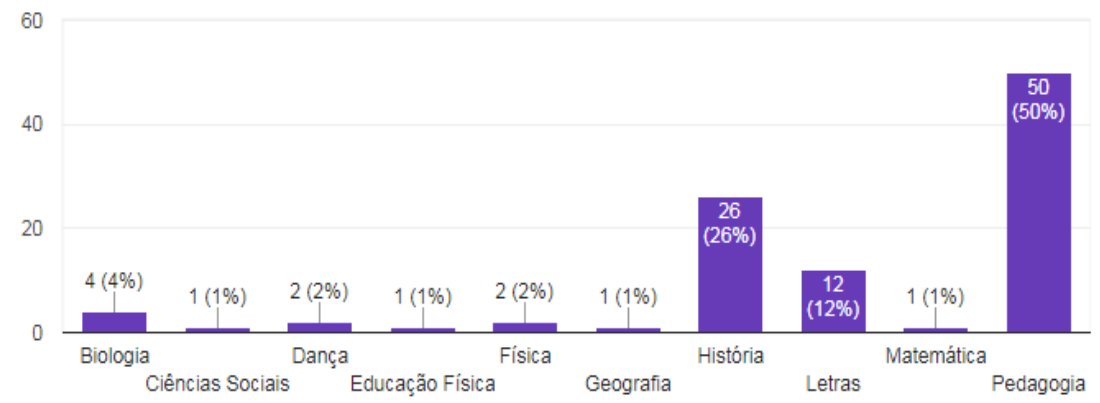

Fonte: As autoras

Desses 100 sujeitos, 11 deles, de 9 cursos distintos, foram selecionados para a etapa de entrevistas. Para viabilizar esse momento, o contato inicial com os primeiros alunos escolhidos ocorreu por meio de ligações telefônicas, no entanto, como muitos não as atendiam, utilizamos um aplicativo de comunicação instantânea como recurso para estabelecermos contato. Apesar de, nesse segundo momento, termos conseguido nos comunicar com os estudantes em todas as tentativas, nem todos aceitaram contribuir com essa etapa de produção de dados. Além disso, houve aqueles que pararam de responder às nossas mensagens, levando-nos a cancelar as participações e a buscar novos sujeitos para compor a pesquisa. Desse modo, apesar de termos estabelecido, como critério primeiro para as entrevistas, a participação de alunos de todos os cursos, o único licenciando do curso de Geografia não constou nessa etapa da produção dos dados, já que parou de responder às nossas mensagens.

Para compor essa etapa, buscamos também estudantes que apresentassem perspectivas diversas sobre o nosso tema de estudo. Para tal, utilizamos, como critério de escolha, a variação nas respostas aos itens do questionário sobre o grau de importância atribuído pelos licenciandos ao desenvolvimento dos trabalhos em grupo em sua formação acadêmica, conforme apontam, a seguir, os Gráficos 2 e 3: 
Gráfico 2 - Preferência por realizar trabalhos em grupo

\section{Como você classifica a importância de desenvolver trabalho em grupo} na sua formação acadêmica?

99 respostas

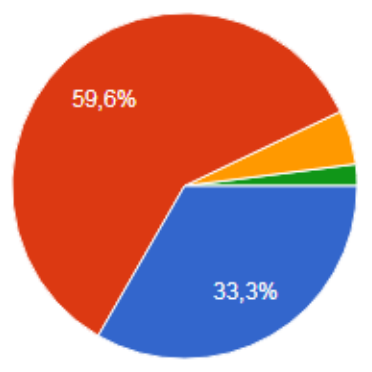

Muito importante

Importante

Pouco importante

Irrelevante

Fonte: As autoras.

Gráfico 3 - Nível de importância dos trabalhos em grupo na formação docente ${ }^{4}$

\section{Você gosta de realizar trabalhos acadêmicos em grupo?}

100 respostas

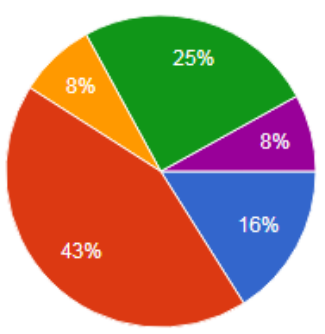

Sim, sempre, independente do grupo

As, vezes, se puder escolher o grupo

Às vezes, depende do número de

integrantes que formará o grupo

Às vezes, depende do tipo de

trabalho

Não, nunca

Fonte: As autoras.

Atrelada à questão indicada no Gráfico 3, acima, uma pergunta aberta pedia para que os estudantes justificassem suas respostas quanto à relevância atribuída aos trabalhos em grupo, tendo essas justificativas sido usadas também como critério de seleção para as entrevistas.

Ao fim da etapa de produção dos dados, emergiram três categorias de análise:

1) O papel assumido pelas tecnologias digitais na realização dos trabalhos em grupo;

2) A construção do saber e das relações interpessoais a partir da utilização das tecnologias digitais no campo educacional;

3) Da esfera educacional para a social: possibilidades e desafios emergentes dos trabalhos em grupo.

A partir dessas categorias, as reflexões trazidas para este artigo giram em torno de: o modo como os licenciandos, participantes da pesquisa, compreendem os trabalhos em

\footnotetext{
${ }^{4}$ Dados omitidos no Gráfico 3: "Pouco importante: 5,1\%; Irrelevante: 2\%”.
} 
grupo; a forma como as tecnologias digitais são utilizadas por eles na realização desses trabalhos e; como ocorre a comunicação e a construção do saber quando mediadas por essas tecnologias.

\title{
O ser humano enquanto ser gregário
}

Zimerman (1997, p. 27 grifo do autor) afirma que "todo ser humano é um grupo", desse modo, como ser gregário por natureza, o indivíduo

\begin{abstract}
[...] somente existe ou subsiste, em função de seus interrelacionamentos grupais. Sempre, desde o nascimento, o indivíduo participa de diferentes grupos, numa constante dialética entre a busca de sua identidade individual e a necessidade de uma identidade grupal e social. (ZIMERMAN, 1997, p. 26)
\end{abstract}

Ao longo de sua vida, inúmeros grupos, de formação espontânea ou não, constituirão o sujeito por meio de uma diversidade de vínculos: desde a família nuclear seu primeiro grupo natural - até "a constituição de novas famílias e de grupos associativos, profissionais, esportivos, sociais, etc.” (ZIMERMAN, 1997, p. 27) Essa característica torna a nós, humanos, seres plurais, de modo que "não há nenhum eu, nem mesmo no mais simples, não há uma unidade, mas um mundo plural, um pequeno firmamento, um caos de formas, de matizes, de situações, de heranças e possibilidades.” (HESSE, 1995, p. 64)

Corroborando a literatura, quando pedimos, nos questionários, que os estudantes justificassem suas respostas acerca da importância atribuída ao ato de trabalhar em grupo, obtivemos respostas referentes à percepção dos seres humanos enquanto seres gregários e, a partir dela, da necessidade de organização coletiva dos indivíduos.

Conforme Laura ${ }^{5}$ (22 anos, aluna de Pedagogia), por exemplo, por relacionar-se a questões sociais, o trabalho em grupo configura-se como essencial em sua formação acadêmica porque "A sociedade é formada por um coletivo de pessoas, portanto, o trabalho em grupo é importante, pois sempre teremos contato com pessoas e precisamos lidar bem nessas ocasiões”. De modo semelhante, para Breno (26, Letras), a importância dessa forma de trabalho está no fato de que "Trabalhos em grupo desenvolvem a capacidade de trabalhar coletivamente".

De acordo com Sennett (2012), faz-se essencial compreender os rituais de cooperação, ou seja, o mutualismo que se estabelece entre os indivíduos, a todo instante, pois a base para o desenvolvimento humano é social. O autor explica que a cooperação, tanto formal como informal, pode se refletir nos simples "rituais de civilidade", como em um "obrigado" ou "por favor". Assim, a habilidade dialógica que nos é essencial pode "percorrer toda a gama de ações implicadas em ouvir com atenção, agir com tato, encontrar pontos de convergência e de gestão da discordância ou evitar a frustração em uma discussão difícil.” (SENNETT, 2012, p. 17)

\footnotetext{
${ }^{5}$ A fim de preservar a identidade dos participantes da pesquisa, todos os nomes utilizados são fictícios. Além disso, os trechos dos dados transcritos neste artigo e produzidos a partir das entrevistas são identificados com a idade e o curso de graduação dos licenciandos.
} 
Nesse sentido, a importância do desenvolvimento de relações interpessoais a partir do trabalho em grupo foi também apontada pelos licenciandos. Vitória (22, Letras), por exemplo, considerou "[...] importante a realização de trabalhos em grupo por desenvolver a habilidade social - saber expor opiniões, respeitar as dos outros e entrar em consenso e pela possibilidade de pensar por outros ângulos/pontos de vista.” Já para Margarida (28, Letras), esse tipo de trabalho "Contribui para desenvolver e construir o conhecimento".

Observamos também que as relações estabelecidas pelos estudantes ultrapassam o âmbito social, estendendo-se para as necessidades relativas ao campo laboral, por exemplo. Na fala de Augusto (37, Dança), o aluno associou o desenvolvimento das interações interpessoais à formação profissional, afirmando que "Os relacionamentos, as interações, nos ajudam em nossa formação pessoal, profissional etc.” Paula (31, Pedagogia) também relatou a importância dessa prática de trabalho, justificando: "Quando adentrarmos no mercado de trabalho precisaremos trabalhar em grupo, com pessoas diferentes. Estaremos a todo momento lidando com pessoas: crianças, famílias, professores, coordenadores, gestão escolar etc."

Dessa maneira, os dados apontaram que a relevância dos grupos e da metodologia de trabalho em grupo para os estudantes gira em torno de questões que abordam, sob uma variedade de ângulos, tanto os aspectos sociais como os pessoais e profissionais.

\section{As perspectivas de licenciandos sobre trabalhos em grupo}

O trabalho em grupo, no contexto educacional, é definido por Cohen e Lotan (2017, p. 1) como um conjunto de estudantes trabalhando em pequenos grupos, "de modo que todos possam participar de uma atividade com tarefas claramente atribuídas”. Ainda que a literatura nos aponte a possível classificação desse trabalho em colaborativo ou cooperativo, quando atribuídas a eles algumas características específicas, também encontramos, em ambos, finalidades comuns para as atividades desenvolvidas em conjunto.

Segundo Torres e Irala (2014, p. 69), "ambas as práticas são complementares e vêm em oposição ao sistema de ensino dominante, baseado numa pedagogia autoritária, hierárquica e unilateral”, consideradas, assim, como metodologias que podem otimizar os processos de ensino e aprendizagem. Ademais, socialmente, "melhora as relações intergrupais, aumentando a confiança e a cordialidade. Ensina habilidades para atuar em equipe que podem ser transferidas para muitas situações, sejam escolares ou da vida adulta.” (COHEN; LOTAN, 2017, p. 7)

Corroborando a literatura, os estudantes participantes da pesquisa resumiram o trabalho em grupo como uma reunião entre duas ou mais pessoas que trabalham visando um objetivo comum. Para Augusto (37, Dança), por exemplo, “grupo seria esse número de pessoas que eles chamam pra fazer um trabalho, e que se estabelece uma relação ali para desenvolver esse trabalho". E complementa: "Na minha cabeça, eu chamo de grupo acima de duas pessoas”. Para Almir (21, Física), “um grupo seria um conjunto de pessoas que tá 
trabalhando pra algum objetivo em comum, e fazer parte do grupo seria contribuir para alcançar esse objetivo".

Torres e Irala (2014, p. 61) apontam a metodologia de trabalho em grupo como uma forma possível de ativar os processos de ensino e aprendizagem, baseando-os na construção do conhecimento como algo social, que ocorre por meio da "interação entre pessoas e não pela transferência do professor para o aluno". Assim, a função do professor seria a de "criar contextos e ambientes que propiciem o aluno desenvolver suas habilidades sociais e cognitivas de modo criativo, na interação com outrem.” (TORRES; IRALA, 2014, p. 61)

Segundo Cohen e Lotan (2017, p. 1) o indivíduo "aprende mais sobre conceitos e ideias quando fala com alguém sobre eles, explica ou discute com outras pessoas, mais do que quando ouve uma palestra ou lê um livro", por exemplo. Essa forma de trabalho também "pode ser mais eficaz do que os métodos tradicionais (assim como outros métodos mais novos) para se chegar a uma compreensão adequada de conceitos abstratos." (COHEN; LOTAN, 2017, p. 10) No entanto, as autoras esclarecem que "isso não quer dizer que ele será mais eficaz em qualquer circunstância.” (COHEN; LOTAN, 2017, p. 10)

Nesse âmbito, os licenciandos consideraram que pode haver condições caracterizadas como ideais para que os trabalhos em grupo sejam realizados. O propósito dessas atividades, para Juan (21, História), por exemplo, deve situar-se no debate acerca do tema de estudo, de modo a "se discutir mais o conteúdo do que tem que ser feito, de trocar ideia." Abordando ainda os meios de desenvolvimento desses trabalhos, Murilo (21, Educação Física) disse, em sua entrevista que: "eu acho que você aprende muito mais dessa forma, porque eu, principalmente, que não sou muito bom em estudar sozinho, eu acho uma possibilidade positiva assim, trabalhar dessa forma."

Assim, para que essa metodologia favoreça a aprendizagem conceitual, segundo Cohen e Lotan (2017), uma condição básica deve ser atendida: a atividade proposta deve requerer pensamento conceitual. Nesse sentido, as atividades conceituais estariam baseadas na leitura, na interpretação de textos complexos, no planejamento de um experimento, bem como na extração de "evidências de textos literários ou informativos para sustentar um argumento, uma análise e reflexão" etc. (COHEN; LOTAN, 2017, p. 11). São nessas tarefas que "os alunos interagem de maneira a ajudar a solucionar equívocos, a aplicar e a comunicar ideias.” (COHEN; LOTAN, 2017, p. 11)

Durante a análise dos dados, identificamos, nas falas dos alunos, a necessidade da interação entre os integrantes do grupo para que o trabalho conjunto seja bem sucedido. Sendo assim, para que se alcance o objetivo comum, o trabalho em grupo não deve resumir-se ao mero somatório dos indivíduos que o compõem, pois, como reflete Fiorentini (2006, p. 7), um grupo requer uma negociação de "responsabilidades a serem assumidas por cada um dos participantes".

Dessa maneira, Murilo (21, Educação Física) afirmou que fazer parte de um grupo seria "estar presente ali no momento de auxiliar nos objetivos que esse grupo propõe, né. 
Então no caso, é... não adianta você tá lá com seu nome no grupo e não fazer nada. Seria auxiliar nos objetivos desse grupo mesmo, isso seria fazer parte dele". Podemos dizer que estamos aí, diante de um trabalho caracteristicamente colaborativo, que tem uma de suas concepções essenciais na interação entre os membros e na negociação, que é estabelecida, por Boavida e Ponte (2002, p. 4), como "fundamental nos inevitáveis momentos de crise". Dessa forma, uma relação amistosa entre os membros do grupo faz-se essencial, pois, como colocou Luigi (22, Pedagogia), conflitos podem emergir "porque geralmente muitos querem expor muitas opiniões e não querem aceitar opiniões de outros”. Dessa maneira, para Flor (30, Pedagogia) "o trabalho em grupo, primeiramente é você ter uma boa relação com os integrantes do grupo. Assim... de confiança também e de pensar também um pouquinho parecido, nunca vai ser igual, mas alguma coisa tem que bater ali, porque senão gera confusão, aí um quer uma coisa, outro não quer e nunca chega num ponto pra ir.”

Nesse sentido, a ideia das negociações, da interação e do diálogo emerge no modo como ocorre a realização das tarefas entre o grupo. Os dados apontaram que, para os participantes da pesquisa, uma divisão que ocorra de forma democrática seria a ideal, pois cada um de seus integrantes trabalharia com o tema e da maneira que lhe fosse mais afim. Segundo Luigi (22, Pedagogia), em alguns trabalhos pode haver a presença de um líder, mas para que algum integrante assuma esse papel dependerá "muito do tema, né, quem se sente mais tranquilo em relação ao tema". Isso, no entanto, não irá excluir a responsabilidade conjunta pelo grupo, assumida por todos os seus membros, o que torna esse tipo trabalho, de acordo com Fiorentini (2006), um trabalho colaborativo.

Apesar de o desenvolvimento das relações interpessoais e a construção do conhecimento serem apontados como potencializadores dos processos de ensino e aprendizagem e, com isso, considerados como possibilidades relativas ao trabalho em grupo, desafios referentes a essa metodologia de trabalho também foram mencionados pelos licenciandos. Um deles está, por exemplo, na diversidade de ideias mobilizadas nas interações estabelecidas uns com os outros.

Enquanto uma metodologia permeada por desafios e possibilidades, para Áurea (24, Letras), as relações interpessoais proporcionadas são fundamentais no sentido "de saber lidar com as pessoas". Nesse sentido, esse modo de trabalho apresenta-se como uma forma de potencializar os processos de ensino e aprendizagem quando

[...] os grupos ajudam a socializar os alunos para funções adultas [...] ensinando-os como ter uma discussão racional e organizada, além de como planejar e realizar uma atividade resultante daquela discussão. Eles formam um conjunto de habilidades das quais muitos adultos frequentemente carecem. Muitas vezes o que os estudantes não sabem é como ouvir os outros e como trabalhar as ideias de outras pessoas. Eles estão mais preocupados em dominar a conversa do que ouvir. Em muitos aspectos do mundo do trabalho e da vida adulta, saber atuar em grupo é fundamental. Portanto, cabe-nos ensinar às crianças como fazê-lo com êxito. (COHEN; LOTAN, 2017, p. 19) 
Na investigação da qual se originou este artigo, apesar de termos realizado a pesquisa em turmas do ensino superior, as reflexões de Cohen e Lotan no trecho citado acima oferecem base teórica que se confirmou na produção dos dados, ao percebemos que as funções relativas aos trabalhos em grupo que essas autoras apontam são também apontadas pelos licenciandos. Quando os estudantes referem-se à socialização como algo relevante, por exemplo, podemos inferir que, ainda na vida adulta, esse é um aspecto essencial para a aprendizagem e que se encaixa tanto no campo pessoal como no social/profissional de suas vidas.

Nessa perspectiva, os dados apontam a relevância dessa metodologia de ensino e aprendizagem como uma possibilidade de preparar o estudante tanto para o meio acadêmico como para o pessoal e social. Nas respostas a um item do questionário pedindo que os alunos justificassem a importância atribuída ao trabalho em grupo, emergiram questões referentes à formação e ao crescimento pessoal; ao meio universitário e à sala de aula como ambientes propícios para se aprender a trabalhar em grupo; à preparação para o mercado de trabalho etc.

Dessa forma, como recurso para a aprendizagem do trabalho em grupo, a sala de aula tradicional e individualizante passa a ser uma classe horizontalizada, fundada em processos de ensino e aprendizagem horizontais, que se baseia na interação entre os estudantes e que não tem como foco o professor. Destarte, conforme explicam Cohen e Lotan, essa aprendizagem sugere um tipo de preparação diferente da utilizada nas salas de aula ditas tradicionais.

\footnotetext{
Quando recebem uma tarefa para ao grupo, solicita-se aos alunos que dependam uns dos outros. Eles agora são responsáveis não apenas pelo seu próprio comportamento, mas pelo comportamento do grupo e pelo resultado dos esforços de todos. Em vez de escutar apenas o professor, devem escutar os outros estudantes. Para que o grupo trabalhe sem problemas, eles devem aprender a solicitar a opinião dos outros, dar às outras pessoas a chance de falar e fazer contribuições breves e sensíveis ao esforço coletivo. Esses são exemplos de novas regras úteis para serem introduzidas antes de começar o trabalho em grupo. (COHEN; LOTAN, 2017, p. 40)
}

Consonantes com as demandas sociais, as capacidades e competências que sociedade ocidental exige do indivíduo estão entre aquelas "que lhes permitam ser capazes de gerir os vários conflitos (identitários), configurados por essas mesmas mudanças” (MACHADO; CÉSAR, 2012, p. 100).

No caso do desenvolvimento das relações interpessoais por meio dos trabalhos em grupo, os estudantes vincularam a eles as exigências sociais e, mais especificamente, as profissionais, ou seja, o seu futuro campo de exercício profissional. Nesse sentido, para Murilo (21, Educação Física) "O desenvolvimento do trabalho em grupo pode auxiliar num melhor preparo para o mercado de trabalho, além do aspecto social que é levado para toda a vida”. Em seu questionário, Paula (31, Pedagogia) também apontou a relevância dessa prática de trabalho. Para ela, "Quando adentrarmos no mercado de trabalho 
precisaremos trabalhar em grupo, com pessoas diferentes. Estaremos a todo momento lidando com pessoas: crianças, famílias, professores, coordenadores, gestão escolar etc."

Percebemos nas falas dos estudantes a superação da dicotomia formação inicial versus formação continuada em torno do desenvolvimento profissional docente. O futuro professor Mauro (21, História) afirmou acreditar na importância das atividades em grupo "no ambiente universitário para proporcionar experiências necessárias para o mercado de trabalho." Para Rosa (Pedagogia, 21), "Em um ambiente escolar, é importante saber trabalhar em grupo. Na universidade é um bom lugar para aprender a trabalhar desse modo." Dessa forma, os dados indiciaram a existência de uma consciência acerca do processo de ser professor, que se constitui a partir de experiências tanto pessoais como profissionais e como algo que ocorre ao longo de toda a vida (MARCELO, 2009).

No entanto, as várias referências atribuídas aos grupos pelos licenciandos deram indícios de que há condições ideais para que um trabalho em grupo seja bem sucedido, e que a colaboração é apontada como uma maneira mais exitosa de se trabalhar em grupo. Características que embasam esse tipo de trabalho, como uma boa interação entre os integrantes do grupo, a busca por um objetivo comum e o diálogo, são consideradas pelos licenciandos como essenciais para que se obtenha êxito.

\section{As tecnologias digitais na construção das relações interpessoais e do saber nos trabalhos em grupo}

Quando mediadas pelas tecnologias digitais, as relações interpessoais e dialógicas apresentam características distintas, se comparadas à comunicação que ocorre num contexto de co-presença. Os dados da pesquisa trouxeram indícios do uso frequente e generalizado das tecnologias digitais no cotidiano dos estudantes. Dos 100 discentes que responderam aos questionários, todos afirmaram acessar à internet diariamente, de modo que apenas as suas formas de acesso variavam.

A literatura aponta que uma outra forma de se relacionar surge com a internet, ao propiciar, "pela primeira vez, a comunicação de muitos com muitos, num momento escolhido, em escala global" (CASTELLS, 2003, p. 8). E, a partir do momento que "nossa prática é baseada na comunicação, e a Internet transforma o modo como nos comunicamos, nossas vidas são profundamente afetadas por essa nova tecnologia da comunicação." (CASTELLS, 2003, p. 10) O seu caráter digital, conforme coloca Nicolau (2008, p. 2), possibilita que se estabeleçam "modelos efetivamente interativos de comunicação".

Indo ao encontro da literatura, Augusto (37, Dança) encara as tecnologias digitais como uma "ponte de comunicação entre as pessoas. Ela é essa ponte quando a gente não consegue se fazer presente assim, esse presente físico mesmo [...]" De modo semelhante, para Juan (21, História), ao permitirem que o tempo e espaço sejam flexibilizados, essas 
tecnologias anulam "a desculpa da distância”, com o simultâneo e o intemporal se encontrando, já que

[...] a comunicação mediada por computadores possibilita o diálogo em tempo real, reunindo pessoas com os mesmos interesses em conversa interativa multilateral, por escrito. Respostas adiadas pelo tempo podem ser superadas com facilidade, pois as novas tecnologias de comunicação oferecem um sentido de instantaneidade que derruba barreiras temporais, como ocorreu com o telefone mas, agora, com maior flexibilidade, permitindo que as partes envolvidas na comunicação deixem passar alguns segundos ou minutos, para trazer outra informação e expandir a esfera de comunicação sem a pressão do telefone, não-adaptado a longos silêncios. (CASTELLS, 1999, p. 553)

Nesse sentido, os dados indicam que a realização de trabalhos em grupo pode ser favorecida pelo uso das tecnologias digitais. Augusto (37, Dança) apontou a possibilidade de utilizar o smartphone para fazer "gravações de vídeo", "alguns registros de fotos" e também "registros de áudio". Já Juan (21, História) disse considerar que a tecnologia digital tem um papel "facilitador enorme", pois, por meio dela, "[...] você não tem que se deslocar de grandes distâncias pra ter a comunicação. Ainda mais que a comunicação hoje tipo, tem vídeo, tem vozes...”, o que, muitas vezes, pode ser pensado como uma alternativa em relação ao meio presencial de encontro. No caso de Luigi (22, Pedagogia), que não reside na cidade onde estuda, essa geografia possibilita os seus encontros com o grupo de trabalho. Também para ele, a internet possui um papel facilitador, a partir do momento em que ela dispensa o encontro físico. Nesse sentido, esse licenciando afirmou que, tanto para ele como para os colegas, essa alternativa se mostra viável, uma vez que possibilita "não ter que ficar direto se encontrando, a gente usa o WhatsApp pra facilitar".

O Gráfico 4, a seguir, aponta o dados apurados, tanto pelos questionários como nas entrevistas, quanto ao modo como os estudantes realizavam os trabalhos em grupo:

\section{Dos trabalhos em grupo propostos em sala de aula que você participa, qual a maneira mais frequente de realizar seus encontros fora de sala?}

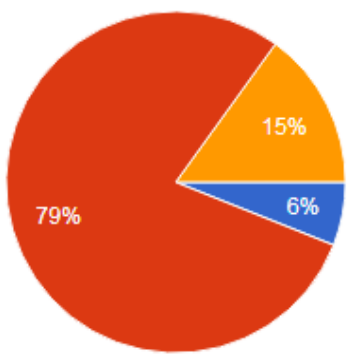

Presencialmente

Presencialmente e via Internet

Via internet

Gráfico 4 - Maneiras de se realizar os encontros em grupo

Fonte: As autoras. 
Os dados do Gráfico 4, indicam-nos a necessidade colocada pelos estudantes de se realizar o trabalho em grupo tanto por meio dos recursos possibilitados pelas tecnologias digitais como presencialmente.

Ainda que Lua (22, Matemática) tenha afirmado realizar, majoritariamente, de forma virtual os encontros de trabalho, a aluna afirmou considerar "essencial o encontro presencial”, pois, de modo virtual, muitas vezes não se consegue transmitir claramente uma mensagem. A conversa virtual, segundo a licencianda, “às vezes gera duplo sentido... aí o presencial é bom por isso, aí você já aborda, se a pessoa não entender tem como você explicar...”. Ao abordar essa questão, Estrela (26, Ciências Biológicas) afirmou que, ainda que grande parte dos trabalhos fosse realizada pela internet, os encontros presenciais eram de sua preferência, pois "muitos dos conflitos são gerados por causa da linguagem de internet”, e a troca simultânea de mensagens "dá aquele desencontro de ideias [...] Aí quando você tá na frente da outra pessoa, você tá vendo enquanto ela tá falando, né, você consegue perceber essas nuances que na internet não tem como.”

Outro aspecto que foi possível perceber com os dados produzidos trata da coexistência de diferentes tipos de tecnologias para a realização desses trabalhos em que diferentes tempos sociais e de saber

[...] estão ligados aos computadores, à impressão, à escrita e os métodos mnemotécnicos das sociedades orais. Todas estas 'antigas' tecnologias intelectuais tiveram, e têm ainda, um papel fundamental no estabelecimento dos referenciais intelectuais e espaçotemporais das sociedades humanas. Nenhum tipo de conhecimento, mesmo que pareça-nos tão natural, por exemplo, quanto a teoria, é independente do uso de tecnologias intelectuais. (LÉVY, 2010, p. 75 grifo do autor)

Indo ao encontro da literatura, foi-nos possível observar, a partir dos dados, que “graus diferentes de avanço e apropriação tecnológica” (VIEIRA PINTO, 2005, p. 8) coexistem, de forma que as tecnologias criadas pelos seres humanos associam-se às tecnologias intelectuais (LÉVY, 2010).

Além da questão comunicacional, outros entraves foram também apontados quanto aos trabalhos realizados virtualmente. Segundo Almir (21, Física), em suas experiências virtuais "basicamente uma pessoa começa a fazer [o trabalho], e aí ninguém mais dá atenção, aí depois a outra pessoa vem e refaz tudo de novo e aí as outras pessoas não fazem nada, e aí, tipo, no final ninguém sabe, ninguém se comunicou direito, e aí tipo, tem um trabalho que é meio Frankstein.”

Ademais, situações relacionadas ao excesso informacional e à necessidade de se utilizar corretamente as tecnologias digitais também estiveram presentes nas falas dos estudantes, corroborando o que aponta a literatura sobre a dicotomia entre a informação e o conhecimento:

Há informações demais e conhecimento de menos no uso da Internet na educação. E há uma certa confusão entre informação e conhecimento. Temos muitos dados, muitas informações disponíveis. Na informação, organizamos os dados dentro de uma lógica, de um código, de uma estrutura determinada. Conhecer é integrar a informação no nosso referencial, no nosso paradigma, 
apropriando-a, tornando-a significativa para nós. O conhecimento não se passa, o conhecimento se cria, constrói-se. (MORAN, 1997, p. 7 grifo do autor)

Plágios, informações equivocadas e problemas de gestão da informação foram apontados pelos licenciandos como aspectos problemáticos de se utilizar as tecnologias digitais para desenvolver trabalhos em grupo. Uma licencianda, por exemplo, queixou-se desses problemas. Ao explicar que a maioria dos seus trabalhos em grupo era realizada com o aplicativo Google Drive - recurso que possibilita o compartilhamento e o acompanhamento simultâneos, por diversos indivíduos, do andamento de uma atividade -, Flor (30, Pedagogia) relatou ter enfrentado problemas quando uma integrante do seu grupo de trabalho não cumpriu a tarefa que lhe coube: "Eu passei a madrugada toda fazendo a parte dela e refazendo o trabalho inteiro, porque tinha partes com plágio que eu comecei a ler e lembrei 'eu li isso na internet', aí eu jogava lá e era copiado, eu tive que refazer tudo de novo."

Algo semelhante ao que relatou a Flor aconteceu, também, com Almir (21, Física), ao participar de um trabalho em grupo realizado via Google Drive: “[...] eu estava tentando fazer [o trabalho], tentando motivar as outras pessoas a fazerem, só que as outras não estavam dando muita atenção. Aí, na véspera da apresentação do trabalho, um outro colega foi, refez tudo, só que ele refez pensando em como ele ia apresentar, então tipo, tinha umas coisas lá que eu não sabia o que era."

Nesse sentido, para o licenciando Murilo (21, Educação Física), o papel facilitador das tecnologias digitais na vida dos estudantes só pode ser consumado caso elas sejam utilizadas de maneira a favorecer, de fato, os processos de ensino e aprendizagem. Segundo o aluno, assim como elas podem contribuir positivamente ao serem associadas aos trabalhos em grupo, esse uso também pode ser nocivo, fazendo com que, consequentemente, o trabalho fique "um pouco deixado de lado". Ainda de acordo com Murilo, em relação à facilidade proporcionada por essas tecnologias, "[...] às vezes as pessoas abusam disso e acabam fazendo de qualquer jeito [o trabalho], deixando pra última hora, justamente por essa facilidade de enviar assim, na hora ali, de não ter que encontrar, de ao mesmo tempo que você tá no WhatsApp, você abre um Google no celular e copia qualquer coisa e joga. Então pode ser que piore também a qualidade do trabalho um роисо."

Nesse caso, como coloca Moran, as possibilidades de busca na internet são inúmeras, no entanto, não basta que a informação seja localizada e que se copie e cole um trecho de texto ou artigo, pois “conhecer se dá ao filtrar, selecionar, avaliar, sintetizar, contextualizar o que é mais relevante, significativo” (MORAN, 1997, p. 7). Dessa forma, o uso das tecnologias digitais pode ou não favorecer, potencializar, a metodologia do trabalho em grupo, a produção de conhecimentos e as relações interpessoais, dependendo do uso que delas faz quem as maneja: 
As redes atraem os estudantes. Eles gostam de navegar, de descobrir endereços novos, de divulgar suas descobertas, de comunicar-se com outros colegas. Mas também podem perder-se entre tantas conexões possíveis, tendo dificuldade em escolher o que é significativo, em fazer relações, em questionar afirmações problemáticas. (MORAN, 1997, p. 7)

Assim, são variadas as conexões e atrativos que as tecnologias digitais oferecem. Nesse caso, como colocou Murilo (21, Educação Física), quando essas tecnologias são utilizadas como mediadoras nos trabalhos em grupo, elas podem apresentar "[...] uma certa desvantagem, porque muita gente tá ali no celular fazendo outras coisas, mexendo em outro aplicativos, não olha o WhatsApp, silencia o grupo do trabalho, não vê...”.

Em contrapartida, o que ocorre num contexto presencial é que as interações face-aface tendem a ser, tipicamente, dialógicas (THOMPSON, 2008). E, diante disso,

\begin{abstract}
Interações cara a cara demandam respostas ou, pelo menos, um comportamento mais atento. Além disso, os alunos se importam com a avaliação de seus colegas; frequentemente, não se recusam a participar e não querem decepcionar o grupo. Por fim, dão suporte aos companheiros para que não fiquem confusos a respeito dos papéis que devem exercer. (COHEN; LOTAN, 2017, p. 3)
\end{abstract}

Nesse sentido, para Murilo (21, Educação Física), a reunião presencial no trabalho em grupo pode ser mais produtiva ao exigir mais de cada aluno ali presente, como colocaram Cohen e Lotan (2017). Segundo o estudante, "Quando você está reunido com o seu grupo, você está sendo praticamente obrigado a entrar no trabalho, porque senão vão te chamar atenção [...]"

Percebemos que a questão dialógica, ou seja, uma relação interpessoal baseada em uma comunicação clara, é fator essencial, como apontaram os licenciandos, para a realização de seus trabalhos. Além dela, a necessidade de se realizar o trabalho em conjunto também faz-se presente. Mas, para isso, é necessário que haja uma relação amistosa entre os membros do grupo.

Conforme Cohen e Lotan (2017, p. 2), a interação entre o grupo faz-se imprescindível porque, "em algum nível, eles precisam uns dos outros para completar a atividade; eles não conseguem fazer todas as partes sozinhos.” Nesse sentido, para Flor (30, Pedagogia) "o trabalho em grupo, primeiramente, é você ter uma boa relação com os integrantes do grupo", de modo que o bom entendimento entre eles influenciará no seu resultado positivo. Augusto (37, Dança) também disse acreditar na boa formação do grupo para o sucesso do trabalho, pois, dependendo dela, "vai atrapalhar no desenvolvimento do trabalho, eu falo por questões... as relações pessoais mesmo, né? Então, às vezes você tem algumas pessoas dos grupos que elas não estão bem, isso atrapalha um pouco o desenvolvimento."

Constatamos que, ainda que a internet propicie a comunicação simultânea entre vários indivíduos e que seus aplicativos, sites e recursos permitam, também, o acesso simultâneo de várias pessoas a um mesmo documento ou arquivo, como no caso do Google Drive, citado pelos entrevistados, essas possibilidades não eximem as tecnologias digitais de possíveis maus usos. Nesse caso, elas podem, inclusive, deixar de contribuir, 
positivamente, para a realização do trabalho em grupo, gerando resultados negativos conforme o uso que delas é feito.

\section{Considerações finais}

Os dados produzidos indicaram que os estudantes concebem os trabalhos em grupo como uma potente metodologia no âmbito dos processos de ensino e aprendizagem. No entanto, é preciso que esse trabalho seja delineado sob determinadas características e propósitos para que seja exitoso. Nesse sentido, a promoção do debate de ideias e, consequentemente, o contato com perspectivas diversas são, para os discentes, formas de construir conhecimentos e de se preparar, tanto para a vida pessoal como para o mercado trabalho, adquirindo experiências sociais essenciais devido aos desafios que as relações interpessoais apresentam.

Em relação à utilização de tecnologias digitais, os dados apontaram um modo específico de interagir socialmente, condicionado por elas, uma vez que a coexistência de diferentes tipos de tecnologias configura o cenário contemporâneo. Por sua vez, quando utilizadas no campo educacional e, mais especificamente, quando associadas aos trabalhos em grupo, essas tecnologias podem favorecer os encontros já que a distância física é por elas anulada. Quando se trata, entretanto, do seu papel no âmbito da comunicação interpessoal, entre os integrantes de um grupo, os estudantes questionam a sua efetividade, apontando como essenciais os encontros presenciais, baseados numa relação dialógica. Outro limite também apresentado pelos licenciandos, referente à utilização dessas tecnologias, está na gama de informações possíveis de serem acessadas por meio da internet. Os dados sinalizam que essa aparente facilidade pode vir a ser um problema, caso o indivíduo não saiba criticar as informações e, a partir daí, produzir conhecimentos. Desse modo, só podem ser aproveitadas as potencialidades que emergem das tecnologias digitais dependendo dos usos que delas faz cada indivíduo.

Objetivamos, com este artigo, contribuir com a literatura no que concerne ao estudo das tecnologias digitais e da metodologia de trabalho em grupo no campo educacional. Intentamos, dessa maneira, expor, a partir das perspectivas de estudantes de licenciaturas, as possibilidades e os limites para a realização de trabalhos em grupos associados às tecnologias digitais, destacando suas potencialidades e apontando a necessidade de delineamentos, para que seja possível atribuirmos um papel significativo a esse tipo de prática na formação de futuros profissionais.

\section{Referências}

AKKARI, Abdeljalil. Internacionalização das políticas educacionais: transformações e desafios. Petrópolis: Vozes, 2011.

BERNSTEIN, Basil. Das pedagogias aos conhecimentos. In: MORAIS, Ana; NEVES, Isabel; DAVIES, Brian; DANIELS, Harry (Orgs.). Rumo a uma Sociologia da Pedagogia: 
a contribuição de Basil Bernstein para pesquisar. Tradução de Tiago Neves. Londres: Peter Lang, 2001.

BOAVIDA, Ana Maria; PONTE, João Pedro. Investigação colaborativa: Potencialidades e problemas. In: Reflectir e investigar sobre a prática profissional, n.1, p. 43-55. Lisboa: APM, $2002 . \quad$ Disponível em: $<$ https://www.researchgate.net/profile/Joao_Ponte2/publication/261176711

_Investigacao_colaborativa_Potencialidades_e_problemas/links/02e7e53374b68a61050000 00.pdf.> Acesso em: 14 ago. 2017.

CASTELLS, Manuel. A Sociedade em Rede. A era da informação: economia, sociedade e cultura. 6. ed. São Paulo: Paz e Terra, 1999.

CASTELLS, Manuel. A galáxia da internet: reflexões sobre a internet, os negócios e a sociedade. Rio de Janeiro: Jorge Zahar Ed., 2003.

COHEN, Elizabeth G.; LOTAN, Rachel A. Planejando o trabalho em grupo. 3 ed. Porto Alegre: Penso, 2017.

DAMIANI, Magda Floriana. Entendendo o trabalho colaborativo em educação e revelando seus benefícios. Educar em revista, Curitiba, n. 31, p. 213-230, 2008. Disponível em: $<$ https://www.scielo.br/scielo.php?pid=S0104-40602008000100013\&script=sci_arttext $>$. Acesso em: 15 ago. 2017.

FARIAS, Lívia Cardoso; DIAS, Rosanne Evangelista. Discursos sobre o uso das TIC na educação em documentos ibero-americanos. Revista Linhas, Florianópolis, v. 14, n. 27, p. 83-104, jul./dez., $2013 . \quad$ Disponível em: <http://www.revistas.udesc.br/index.php/linhas/article/view/198472381 427201383> Acesso em: 19 jun. 2017.

FIORENTINI, Dario. Pesquisar práticas colaborativas ou pesquisar colaborativamente? In: BORBA, Marcelo de Carvalho; ARAÚJO, Jussara de Loiola. (Orgs.) Pesquisa qualitativa em educação matemática. 2. ed. Belo Horizonte: Autêntica, 2006. p. 49-78.

HARGREAVES, Andy. Os professores em tempos de mudança. Lisboa: McGraw-Hill, 1998.

HESSE, Hermann. O Lobo da Estepe. Editora Record, 1995.

HYPOLITO, Álvaro Moreira; GRISHCKE, Paulo Eduardo. Trabalho imaterial e trabalho docente. Educação (UFSM), v. 38, n. 3, p. 507-522, set./dez., 2013. Disponível em: $<$ https://periodicos. ufsm.br/reveducacao/article/view/8998>. Acesso em: 08 out. 2018.

LÉVY, Pierre. Tecnologias da Inteligência: o futuro do pensamento na era da informática. 2. ed. São Paulo: Editora 34, 2010.

LIMA, Mariana Aparecida Toledo de. As perspectivas de estudantes de licenciatura sobre o papel das tecnologias digitais nos trabalho em grupo. 2019. 128 f. Dissertação (Mestrado em Educação) - Departamento de Educação, Universidade Federal de Viçosa, Viçosa.2019.

MACHADO, Ricardo; CÉSAR, Margarida. Trabalho colaborativo e representações sociais: contributos para a promoção do sucesso escolar em matemática. Interacções, v. 8, n. 20, p. 98-140, 2012. Disponível em: <https://repositorio.ul.pt/bitstream/10451/5963/1/Machado\%20\%26\%20 C\%C3\%A9sar.pdf>. Acesso em: 21 ago. 2017.

MARCELO, Carlos. Desenvolvimento profissional docente: passado e futuro. Sísifo, Revista de ciências da educação, n. 8, p. 7-22, jan/abr., 2009. Disponível em: $<$ http://www.unitau.br/files/arquivos/category_1/MARCELO__Desenvolvimento_Profissional_Docente_passado_e_futuro_1386180263.pdf $>$. Acesso em: 13 maio 2017.

MORAN, José Manuel. Como utilizar a Internet na educação. Ciência da informação, Brasília, v. 26, n. 2, maio/ago, 1997. Disponível em: $<$ https://www.scielo.br/scielo.php?script=sci_arttext\&pid= S0100-19651997000200006 $>$. Acesso em: 20 fev. 2019. 
NICOLAU, Marcos. Fluxo, conexão, relacionamento: um modelo comunicacional para as mídias interativas. Culturas midiáticas, v. 1, n. 1, jul./dez., 2008. Disponível em: $<$ https://www.periodicos.ufpb.br/index.php/cm/article/viewFile/11624/6664>. Acesso em: 20 fev. 2019.

ONU. UIT: 3,7 bilhões de pessoas ainda não têm acesso à Internet no mundo. 2016. Disponível em: <https://nacoesunidas.org/uit-37-bilhoes-de-pessoas-ainda-nao-tem-acessoa-internet-no- mundo/ > . Acesso em: 27 fev. 2019.

OUTEIRAL, José Ottoni. O trabalho com grupos na escola. In: ZIMERMAN, David E.; OSORIO, Luiz Carlos et al. Como Trabalhamos Com Grupos. Porto Alegre: Artes Médicas, 1997. p. 359-372.

SANTOS, Fábio Maurício Fonseca; ALVES, André Luiz; PORTO, Cristiane de Magalhães. Educação e Tecnologias. Revista Científica da FASETE, p. 44-61, 2018. Disponível

em: $<$ https://www.unirios.edu.br/revistarios/media/revistas/2018/17/educacao_e_tecnologias.pd f>. Acesso em: 09 jul. 2020.

SENNETT, Richard. Juntos: os rituais, os prazeres e a política da cooperação. Rio de Janeiro: Record, 2012.

SOARES, Wellington Nora; VASCONCELOS, Fernanda Carla Wasner. A Utilização de Tecnologias de Informação e Comunicação Como Recurso Didático Para a Promoção da Educação Ambiental. Tecnologias na Educação, Belo Horizonte, v. 24, n. 1, p. 51-66, jul.,2018. Disponível em: <http://tecedu.pro.br/wp-content/uploads/2018/08/Art17-vol.25Junho-2018.pdf.> Acesso em: 09 jul. 2020.

THOMPSON, John B. A nova visibilidade. Matrizes, v. 1, n. 2, p. 15-38, 2008. Disponível em: $\quad$ <file:///C:/Users/user/Downloads/38190-Texto\%20do\%20artigo-44941-1-1020120814.pdf.> Acesso em: 26 fev. 2019.

TORRES, Patrícia Lupion; IRALA, Erson Adriano Freitas. Aprendizagem colaborativa: teoria e prática. In: TORRES, Patrícia Lupiom (Org.) Complexidade: redes e conexões na produção do conhecimento. Curitiba: SENAR-PR, p. 61-93, 2014.

TORRES, Patrícia Lupion; ALCANTARA, Paulo R.; IRALA, Erson Adriano Freitas. Grupos de consenso: uma proposta de aprendizagem colaborativa para o processo de ensino-aprendizagem. Revista diálogo educacional, Curitiba, v. 4, n. 13, p. 129-145, 2004. Disponível em:

$<$ https://periodicos.pucpr.br/index.php/dialogoeducacional/article/view/7052/6932>.

Acesso em: 25 jan. 2018.

VIEIRA-PINTO, Álvaro. O conceito de tecnologia. Rio de Janeiro: Contraponto, 2005.

ZIMERMAN, David E. Fundamentos teóricos. In: ZIMERMAN, David E.; OSORIO, Luiz Carlos et al. Como Trabalhamos Com Grupos. Porto Alegre: Artes Médicas, 1997. p. 23-32.

Recebido em: 26/06/2019

Aprovado em: 08/07/2020 